\title{
ЧЕРНЕНИЕ ПОВЕРХНОСТИ МЕТАЛЛОВ ПИКОСЕКУНДНЫМ ЛАЗЕРОМ
}

\author{
Ю.А. Кулагин, В.Г. Бутенко, Е. О. Баранов
}

ЮРИЙ АЛЕКСАНДРОВИЧКУЛАГИН - д.т.н., профессор, ведущчий научный сотрудник ФГУП «ЦНИИХМ». E-mail:kulaginyua@mail.ru.

ВЛАДИМИР ГРИГОРЬЕВИЧ БУТЕНКО - к.т.н., заместитель директора МЦАИ РАН по научной работе. E-mail: cnfc2009@mail.ru.

ЕВГЕНИЙ ОЛЕГОВИЧ БАРАНОВ - младший научный сотрудник ФГУП «ЦНИИХМ». E-mail: mangst@yandex.ru.

115487 г. Москва, ул. Нагатинская, д. 16а, Федеральное государственное унитарное предприятие «Центральный научно-исследовательский институт химии и механики» (ФГУП «ЦНИИХМ»).

117997 г. Москва, ул. Профсоюзная, д. 65, стр. 6, Федеральное государственное бюджетное учреждение науки Межведомственный центр аналитических исследований в области физики, химии и биологии при Президиуме Российской академии наук (МЦАИ РАН).

Для уменьшения помеховых излучений в бортовой оптико-электронной системе космических аппаратов исследовалась возможность создания и изготовления черных покрытий для внутренних поверхностей оборудования и бленд с минимальным светорассеиванием (с низким коэффициентом отражения в оптическом диапазоне от 200 нм до 1000 нм). Проведено сравнение различных методов чернения поверхностей и показано, что микро-наноструктурирование поверхности алюминия пикосекундным лазером позволяет получать коэффициент отражения менее 0,1% и является наиболее эффективным и экономичным.

Ключевые слова: чернение, поглощение, отражение, лазер, алюминий, медь, покрытие.

\section{BLACKENING OF METAL SURFACES WITH A PICOSECOND LASER}

\author{
Yu.A. Kulagin ${ }^{1}$, V. G. Butenko ${ }^{2}$, E. O. Baranov ${ }^{1}$ \\ ${ }^{1} 6 a$, Nagatinskaya, Moscow, 115487, Russia. Central research Institute of chemistry and mechanics (FSUE \\ CNIICHM).
}

${ }^{2} 65$ Profsoyuznaya st., Moscow, 117997, Russia. Interdepartmental center for analytical research in the field of physics, chemistry and biology under the Presidium of the RAS (MZAI RAN).

To reduce interference emissions in the on-board optical-electronic system of spacecraft, the possibility of creating and manufacturing black coatings for the inner surfaces of equipment and blends with minimal light scattering (with a low reflection coefficient in the optical range from $200 \mathrm{~nm}$ to $1000 \mathrm{~nm}$ ) was investigated. A comparison of various methods of surface blackening is carried out and it is shown that micro-nanostructuring of the aluminum 
surface with a picosecond laser allows obtaining a reflection coefficient of less than $0,1 \%$ and is the most effective and economical.

Keywords: blackening, absorption, reflection, laser, aluminum, copper, plating.

Разработка высококачественных электропроводящих поглощающих покрытий на различных материалах находит широкое применение в аэрокосмической, электронной и приборостроительной отраслях. Для космических аппаратов помехозащищенность оптических приборов от различных излучающих световых помех является важным показателем работоспособности бортовых оптикоэлектронных систем (ОЭС) наблюдения. Для их защиты необходимо нанесение электропроводящих покрытий с низким коэффициентом отражения на внутреннюю поверхность оборудования. Одной из основных проблем, в данном случае, является то, что используемые в аэрокосмической отрасли материалы (алюминий, титан, медь и др.) в оптическом и ИК диапазоне имеют высокие коэффициенты отражения (до 97 \%) [1], что является абсолютно неприемлемым для использования в конструкции оптических средств наблюдения.

Целью работы являлись разработка методики изготовления черных покрытий для внутренних поверхностей ОЭС и бленд с минимальным светорассеиванием (с низким коэффициентом отражения в оптическом диапазоне от 200 нм до 1000 нм) с использованием лазерного микро- и наноструктурирования поверхности металла. Данная методика применялась нами для различных материалов: алюминий, медь, кремний, серебро, золото, титан и др. Наилучшие результаты были получены при обработке пикосекундным лазером (532 нм) поверхности алюминия.

Существуют различные способы чернения металлов. В настоящий момент самым распространенным методом является химическое травление алюминия. Это самый простой и распространенный метод. Наилучший результат был получен при химическом оксидировании с ортофосфорной кислотой. Однако высокие коэффициенты отражения $\mathrm{K}_{\text {отр }} \sim 5 \%$ и низкая износостойкость поверхности не позволяют использовать эти покрытия в ОЭС.

Зарубежными и отечественными научно-исследовательскими организациями ведутся исследования по созданию наноматериалов, в том числе для перспективных покрытий с низким коэффициентом отражения. Например, британская компания Surrey NanoSystems разработала технологию создания материала на основе углерод- ных нанотрубок (Vantablack) с коэффициентом отражения 0,035 \% в видимом диапазоне. Данный материал может наноситься на изделия из меди и алюминия, снижая их коэффициент отражения [2]. Исследователи из Массачусетского технологического института в 2019 году создали новый материал, который, по их утверждению, минимум в 10 раз черней, чем любой другой из существующих материалов. Необычайную черноту новому материалу придает «лес» из вертикально ориентированных углеродных нанотрубок, которые представляют собой электропроводящие микроскопические полые нити из углерода. Углеродные нанотрубки были выращены электрохимическим путем на поверхности токопроводящей алюминиевой фольги. Проведенные лабораторные испытания полученного материала показали, что его поверхность отражает только $0,005 \%$ от падающего на нее света.

Нанесение «леса» углеродных нанотрубок на конструкционные материалы осуществляется при деструкции газообразных углеводородов плазмой электрического разряда, возникающей между электродом и металлической поверхностью подложки, которую используют в качестве заземленного противоэлектрода [3]. При этом процессы синтеза нанотрубок и их осаждения на подложке осуществляются одновременно. Важную роль при этом играют адгезионные свойства подложки.

Еще одним способом чернения является лазерная обработка поверхности металла. В статье «Nanosecond pulsed laser blackening of copper» [4] продемонстрировано чернение меди наносекундным лазером с длиной волны 532 нм. По результатам экспериментов было продемонстрировано снижение коэффициента отражения до 3 \% для длин волн 250-2500 нм. В отличие от предыдущих способов, чернение меди лазером показывает наименьшую трудоемкость и наибольшую производительность.

В данной работе исследована возможность чернения металлов пикосекундным лазером с длинной волны 532 нм. Для этой цели был использован стенд (рис. 1) с пикосекундным лазерным комплексом Duetto (1). Лазерное излучение посредством системы диэлектрических зеркал (2) транспортировалось в лазерную головку LDesigner (3). Лазерная головка осуществляла фокусировку 


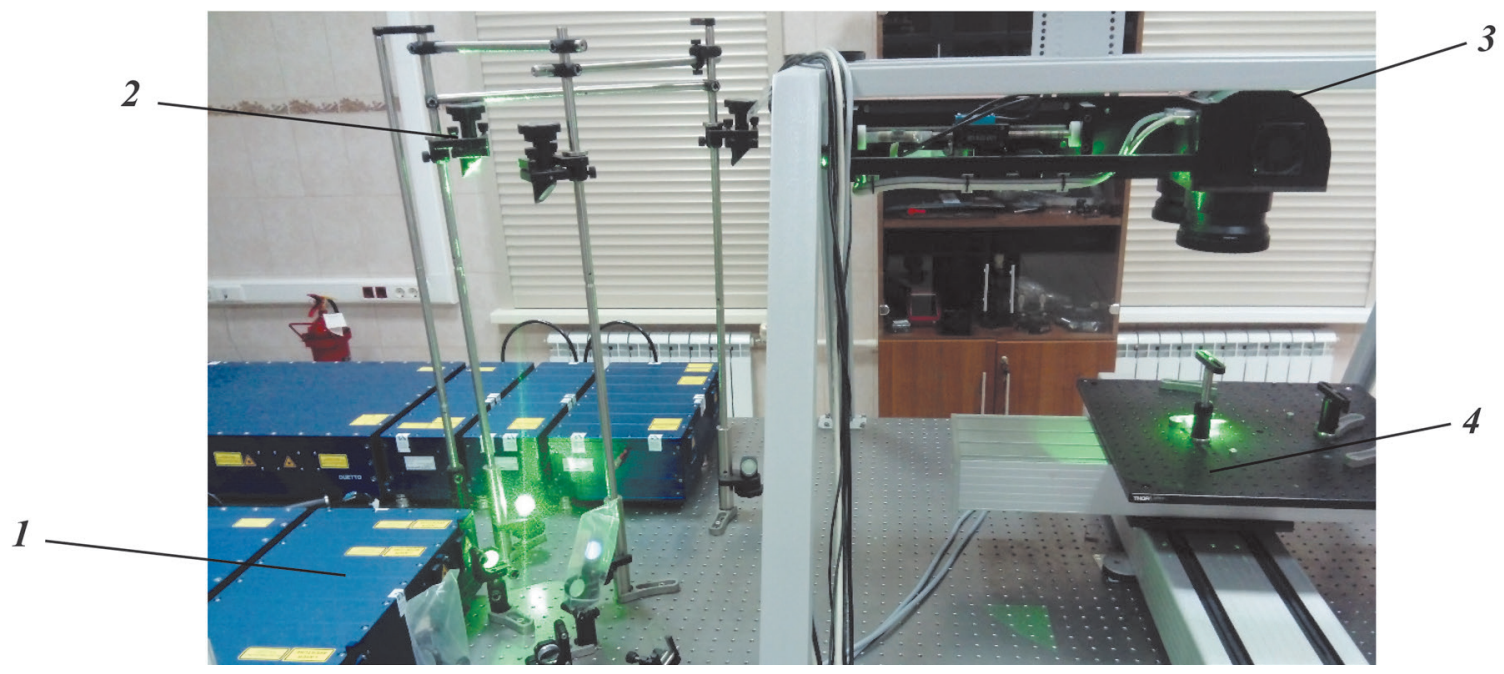

Рис. 1. Стенд для обработки лабораторных образцов

1 - пикосекундный лазер; 2 - диэлектрические зеркала; 3 -лазерная головка; 4 - двухкоординатный стол

излучения на лабораторные образцы, закрепленные на двухкоординатном столе (4).

Для чернения металлов использовался метод лазерной абляции, заключающийся в воздействии на обрабатываемую поверхность мощного фокусированного пикосекундного лазерного излучения с плотностью более $106 \mathrm{BT} / \mathrm{cm}^{2}$. В результате возникающего оптического взрыва с поверхности происходит локальный выброс плазменного облака атомов вещества. В канале выброса в условиях интенсивного отвода тепла формируется столбчатый след испаренной порции вещества. Сканирование поверхности обеспечивает создание на ней структурированного на микро- и наноуровне столбчатого рельефа, профиль, размеры и периодичностью чередования элементов которого задаются режимом лазерной обработки.

Длительность импульса лазера составляла $10 \pm 2$ пс. Обработка лабораторных образцов осуществлялась с частотой 50 кГц при средней мощности излучения (Р) 11,2 Вт. Лазерная головка позволяла регулировать заливку лабораторных образцов, определяя степень наложения импульсов друг на друга за счет таких параметров как линейная скорость лазерного пучка $(\mathrm{V})$ и количество линий на миллиметр (C). Схема процесса заливки продемонстрирована на рис. 2.

В качестве лабораторных образцов использовались пластинки из алюминия размерами $25 \times 25$ мм. Лазерное структурирование поверхности алюминия проводилось при различных режимах. На рис. 3 показана фотография одного из лабораторных образцов. В табл. 1 приведены три режимы обработки поверхности алюминия.

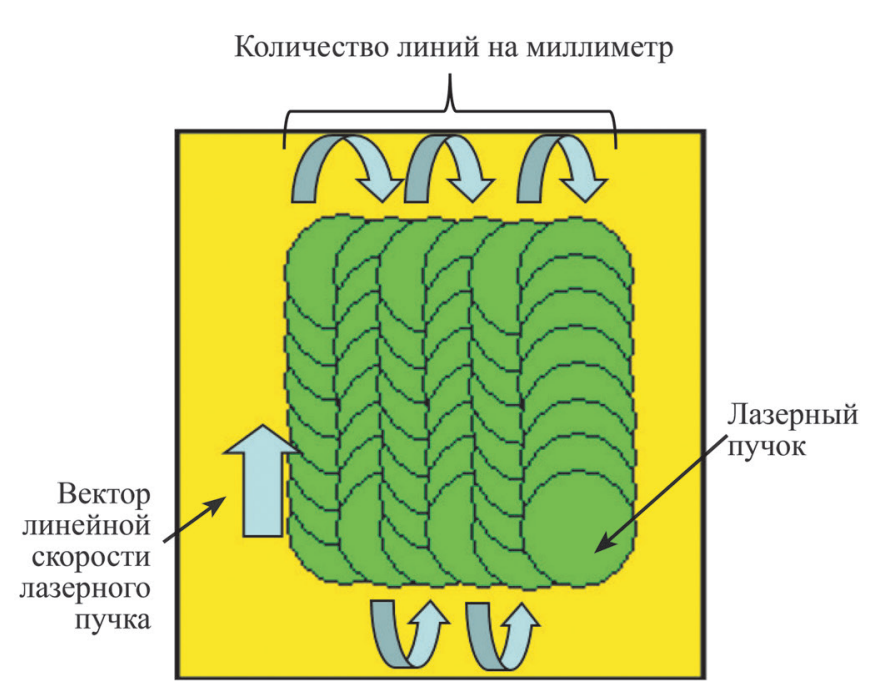

Рис. 2. Схема процесса заливки

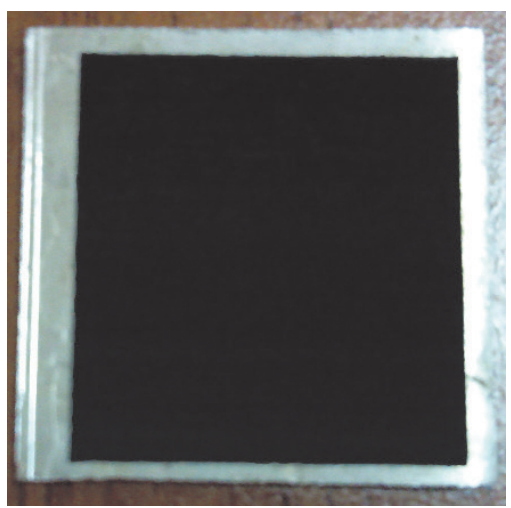

Рис. 3. Лабораторный образец 
Режимы обработки лабораторных образцов

\begin{tabular}{ccccc}
\hline № образца & Материал & $\mathbf{V}$, мм/сек & $\mathbf{C , ~ л и н и и ̆ / м м ~}$ & Р, Вт \\
\hline 1 & алюминий & 50 & 15 & 11,2 \\
2 & алюминий & 20 & 50 & 11,2 \\
3 & алюминий & 20 & 100 & 11,2 \\
\hline
\end{tabular}

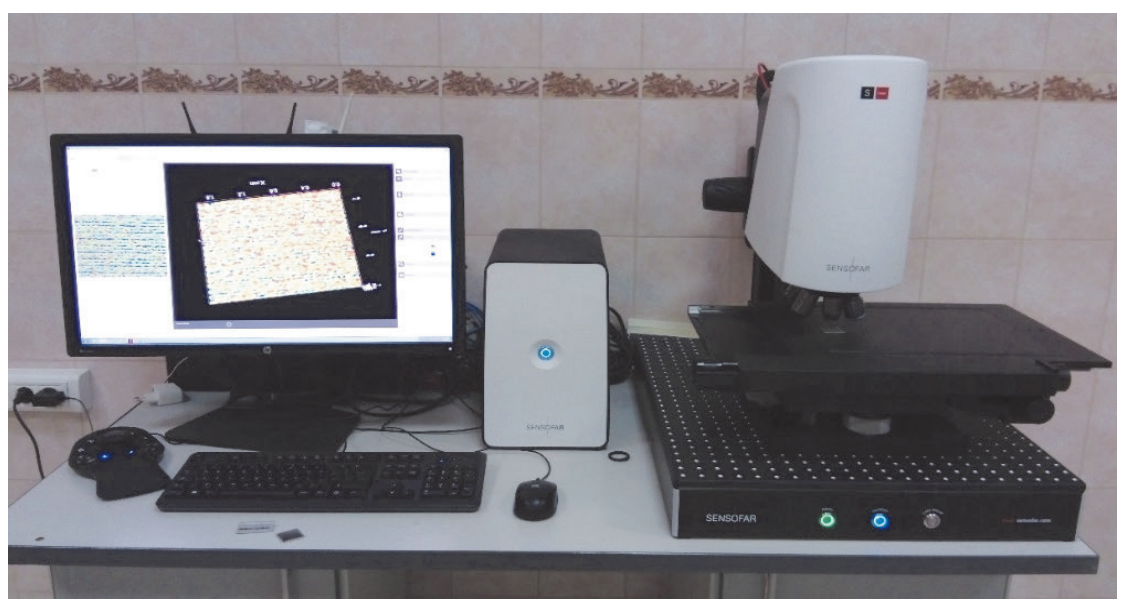

Рис. 4. Профилометр-конфокальный микроскоп Sensofar Sneox

После лазерной обработки поверхность лабораторных образцов исследовалась на 3D профилометре-конфокальном микроскопе Sensofar Sneox (рис. 4). Особое внимание уделялось поверхностным-периодическим структурам, возникающим в результате импульсного воздействия лазерного излучения на материал. Физика возникновения подобных структур заключается в том, что в месте контакта образца и сфокусированного лазерного излучения за счет высоких значений энергии на единицу площади происходит микровзрыв с выбросом материала. При этом, происходит быстрое остывание поверхности с формированием периодической микро-наноструктуры.

Профилометрия исследований представлена на рис. 5.

На приведенных рисунках видно наличие поверхностных-периодических структур. Высота их пиков, а также пространственная ориентация оказывает влияние на коэффициент отражения.
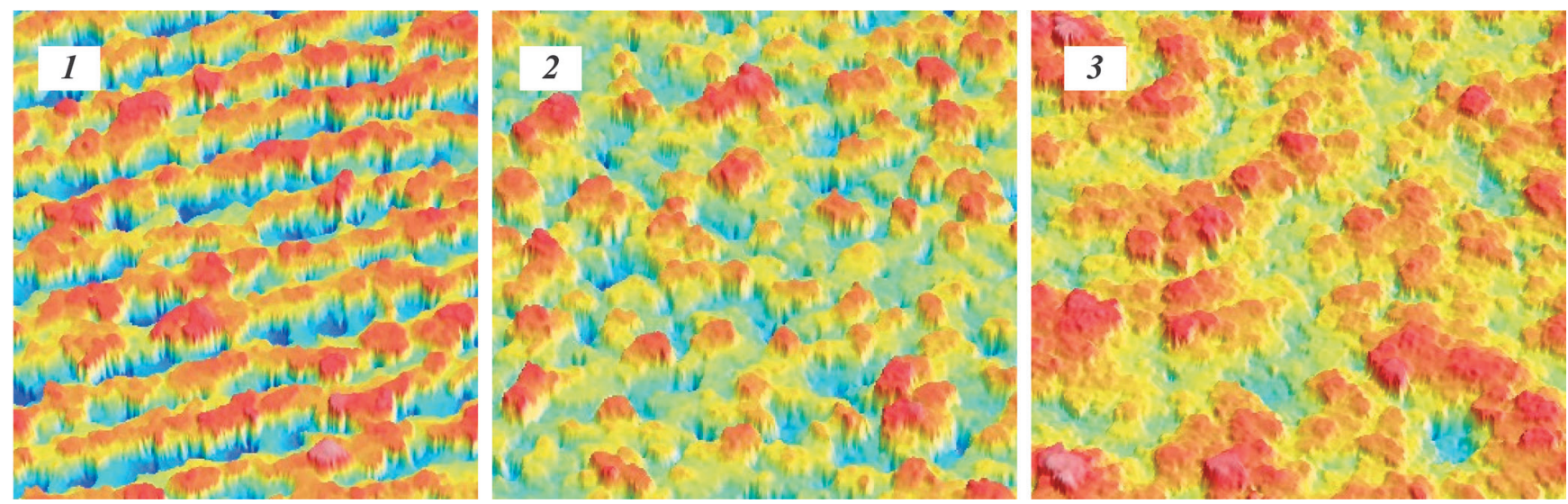

Рис. 5. Профилометрия исследований экспериментальных образцов

(цифрами 1-3 отмечены режимы обработки) 
Параметры шероховатости лабораторных образцов

\begin{tabular}{ccccc}
\hline № образца & $\mathrm{S}_{\mathrm{a}}$, нм & $\mathrm{S}_{\mathrm{z}}$, нм & $\mathrm{S}_{\mathrm{mx}}$, Hм & $\mathrm{S}_{\mathrm{my}}$, нм \\
\hline 1 & 37 & 276 & 125 & 68 \\
2 & 18 & 210 & 115 & 154 \\
3 & 20 & 317 & 219 & 172 \\
\hline
\end{tabular}

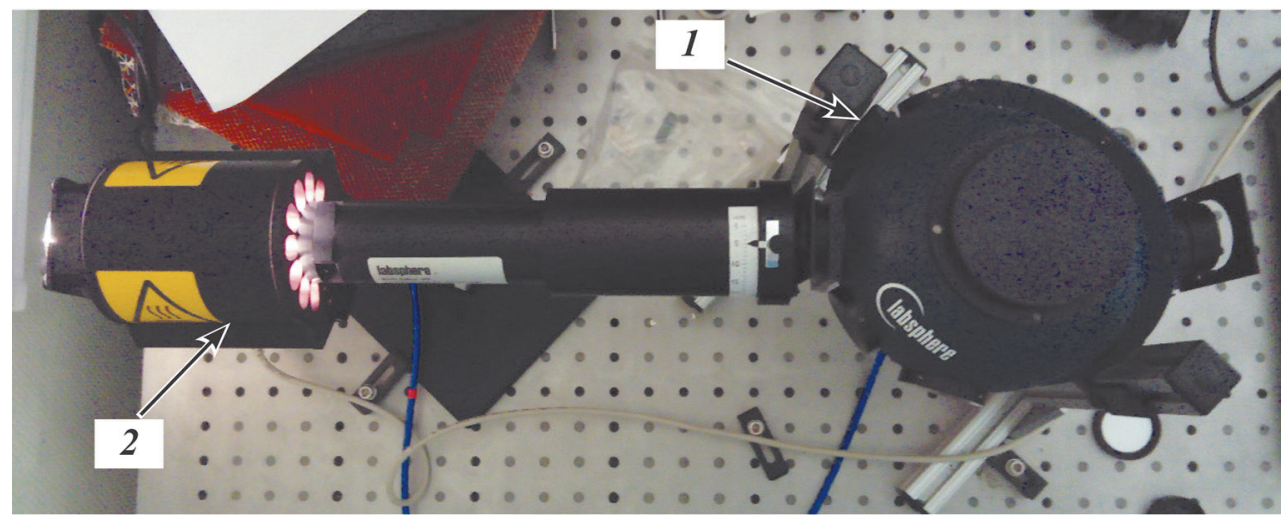

Рис. 6. Стенд для измерения коэффициента отражения

Результаты профилометрии, демонстрирующие параметры шероховатости образцов представлены в табл. 2.

В табл. 2 параметр $\mathrm{S}_{\mathrm{a}}$ обозначает среднее арифметическое из абсолютных значений отклонений профиля в пределах сканируемой площади, $\mathrm{S}_{\mathrm{z}}-$ сумму средних абсолютных значений высот пяти наибольших выступов профиля и глубин пяти наибольших впадин профиля в пределах сканируемой площади. Для представленных в таблице значений площадь сканирования составляла 1,6 мм². Также в таблице отражены значения среднего шага неровностей $\mathrm{S}_{\mathrm{m}}$ по осям х и у.

Измерение коэффициента отражения проводилось на специальном стенде (рис. 6), состоящем из сферы Labsphere (1) и осветителя Koehler Illuminator KI-120 (2).

Лабораторный образец располагался на внутренней поверхности сферы. Осветитель осуществлял подсветку лабораторного образца сфокусированным пучком света, диаметром 12 мм с заданной интенсивностью. Сфера регистрировала интенсивность полного отражения света Коэффициент отражения рассчитывался с помощью программного обеспечения блока управления по соотношению:

$$
K_{\text {omp }}=\frac{I_{\text {omp }}}{I_{o}},
$$

Перед экспериментальными измерениями проводилась тарировка стенда с использованием эталона диффузного отражения WS-1-SL, изготовленного из материала Spectralon, с коэффициентом отражения 0,99. Коэффициент отражения экспериментальных образцов рассчитывался относительно используемого эталона. В таблице 3 приведены измеренные значения коэффициентов отражения для различных режимов лазерного структурирования поверхности образцов.

Таблица 3

\section{Результаты измерений}

\begin{tabular}{cc}
\hline № образца & $\mathbf{K}_{\text {отр }}(\mathbf{\%})$ \\
\hline 1 & 0,1 \\
2 & 0,7 \\
3 & 3,2 \\
\hline
\end{tabular}

Анализируя данные таблице 1 и результаты, приведенные в таблице 2, можно сделать вывод о том, что для достижения наилучших результатов по чернению алюминия подходят более щадящие режимы лазерной обработки. Это объясняется выбросами и последующим оседанием на обрабатываемую поверхность микро- наночастиц алюминия в процессе лазерной абляции. Более щадящие режимы позволяют избежать загрязнения обрабатываемой поверхности данными частицами. Также, на основе результатов измерений в таблице 2, можно сделать вывод, что образец № 3 пока- 


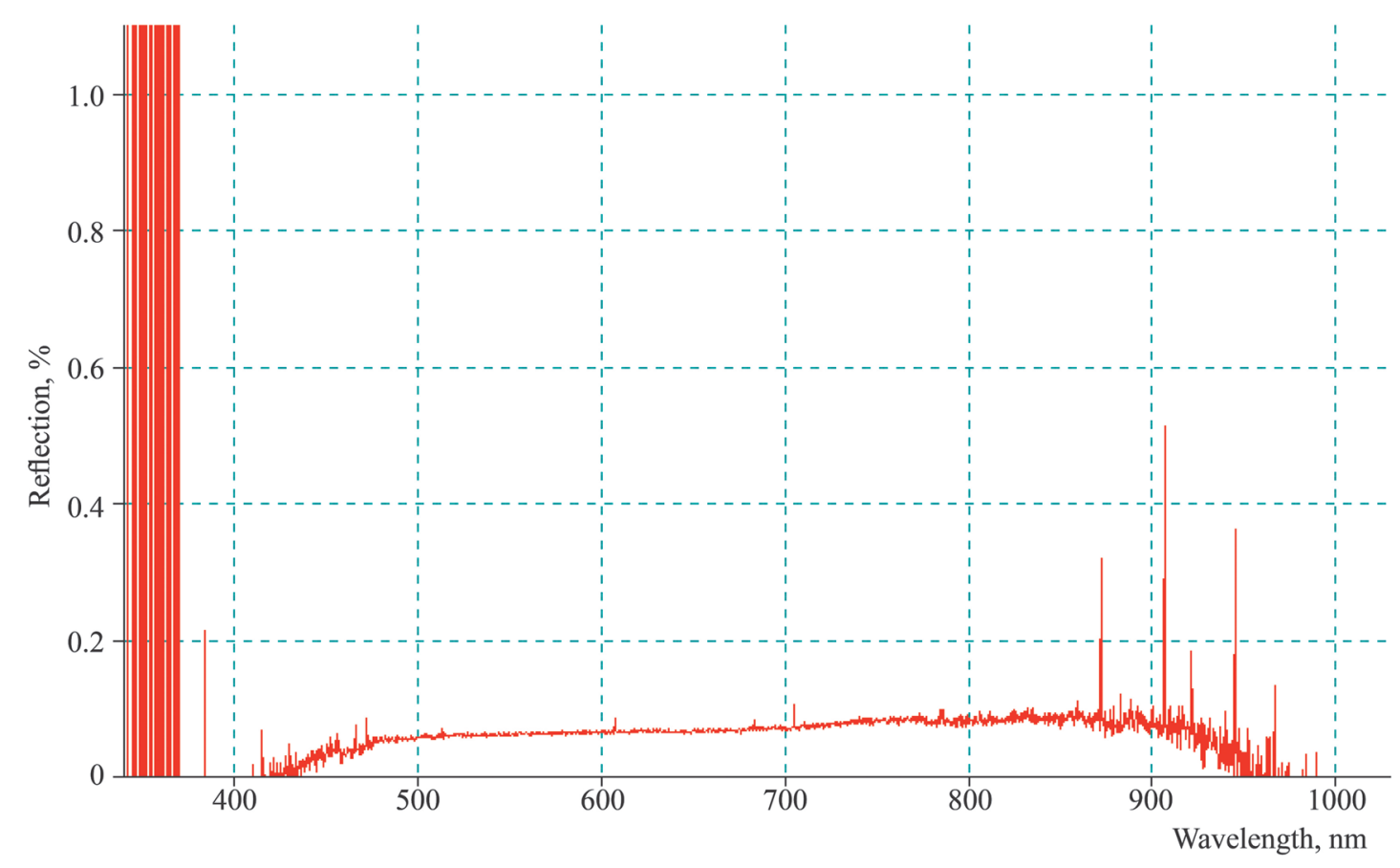

Рис. 7. Зависимость коэффициента отражения от длины волны падающего излучения

зал наихудший результат из-за наибольшего шага неровностей. Образец № 1, согласно параметру $\mathrm{S}_{z}$, имел наиболее глубокие впадины шероховатости, наименьший шаг неровностей по оси у и примерно одинаковый шаг неровностей с образцом №2 по оси х. Именно образец № 1 и показал наилучший результат при измерении $\mathrm{K}_{\text {отр }} \sim 0,1$.

Ни рис. 7 изображена зависимость коэффициента отражения от длины волны падающего излучения для образца № 1.

\section{Выводы}

В процессе выполнения работы была продемонстрирована возможность значительного снижения коэффициента отражения алюминия до $0,1 \%$ при структурировании поверхности пикосекундным лазером. Результаты исследования показали зависимость коэффициента отражения от глубины и периода неровностей. Коэффициент отражения падает при увеличении глубины неровностей и уменьшении шага шероховатости. Это говорит о возможности дальнейшего снижения коэффициента отражения с помощью обработки поверхности лазером. Таким образом, появляется задача поиска оптимальных параметров шероховатости для наименьшего коэффициента отражения.
Покрытия на пластинах и фольге из алюминия, полученные методом лазерного нано-микроструктурирования поверхности являются экономически выгодными и удовлетворяют требованиям для ОЭС космического базирования (механические характеристики, вибрации, перепады давления, температуры (от минус $60{ }^{\circ} \mathrm{C}$ до $+160{ }^{\circ} \mathrm{C}$ - для низкоорбитальных; от минус $196^{\circ} \mathrm{C}$ до $+580{ }^{\circ} \mathrm{C}$ - для межпланетных станций). Кроме того, они обладают высокими адгезионными свойствами и равномерно распределенной электропроводностью, что позволяет использовать их в качестве подложки совместно с другими методами, например, с напылением нанотрубок.

\section{Литература}

1. Звелто О. Принципы лазеров. - М.: Мир, 1990. $719 \mathrm{c}$.

2. Theocharous E., Chunnilall Ch. J., Mole R., Gibbs D., Fox N., Shang N., Howlett G., Jensen B., Taylor R., Reveles J., Harris O., Ahmed N. Optics Express. 2014. V. 22(6). P. 7290-7307.

3. Адамчук Ю.О., Богуславский Л.3., Синчук А.В. Электронная обработка материалов. 2017. V. 53(6). P. 1-7.

4. Tang G., Hourd A.C., Abdolvand A. Applied Physics Letters. 2012. P. 101. 